\title{
Safer Tractor Operations for Florida's Privately Owned and Operated Farms and Ranches ${ }^{1}$
}

Carol J. Lehtola and Charles M. Brown ${ }^{2}$

\section{In the Headlines!}

\section{Power Take-off Entanglement Kills 17-Year-Old}

A 17-year-old high school student working part-time for a neighboring farmer was killed when his clothing was caught by an unshielded power take-off (PTO) driveline of a grinder-mixer. He had been helping the farmer add sacks of feed supplement to the ground corn in the mixer.

The task was almost complete and the farmer was closing the hammer mill cover while the youth stood near the PTO driveline in front of the flywheel. Although the flywheel was disengaged, the PTO driveline and unshielded flywheel clutch were rotating at about 200 revolutions per minute (RPM).

The farmer heard a thump, then noticed that the boy had been caught and entangled around the driveline at the flywheel clutch, which resulted in severe head injuries. He died instantly. The official cause of death was listed as "decapitation." (Further discussion of this incident is given in Appendix 1, near the end of this publication.)

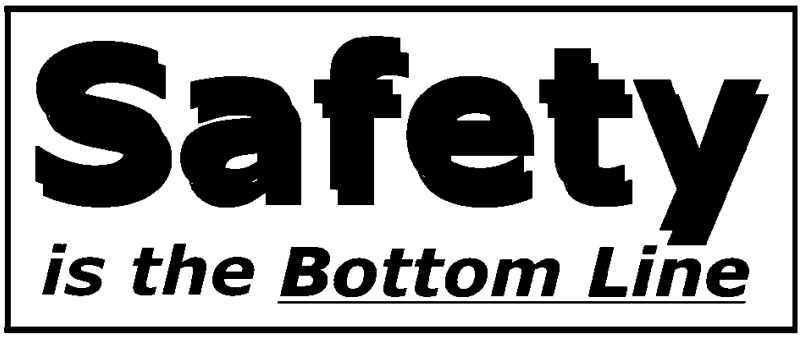

Tractor Overturn Crushes Operator

In 1995, a 39-year-old farmer was killed while loading hay onto a haywagon. The man was working with his two sons loading square bales of hay in a rolling hayfield with mild contours. He was using a narrow-front tractor equipped with a front end loader and powered hayfork. The wagon was unattached to the tractor and left on a slight incline. While loading the second layer of haybales on the wagon, the farmer used the front end loader to push and align the bales. The wagon started to roll slowly backwards. The older son jumped off and grabbed the tongue of the wagon trying to steer the wagon uphill.

His father quickly backed off and drove the tractor to the downhill side of the wagon and tried to place the loader in front of the moving wagon. The wagon hit the raised front end loader form the right side, overturning the tractor sideways, crushing the

1. This document is CIR 1250,one of a series of the Agricultural and Biological Engineering Department, Florida Cooperative Extension Service, Institute of Food and Agricultural Sciences, University of Florida. First published September 2002. Please visit the EDIS Web site at http://edis.ifas.ufl.edu.

2. Carol J. Lehtola, associate professor, Department of Agricultural and Biological Engineering, and Extension Agricultural Safety Specialist, and Charles M. Brown, Assistant Coordinator for Agricultural Safety and Health, Institute of Food and Agricultural Sciences, University of Florida, Gainesville, 32611. 
farmer under the right rear tire, killing him instantly. The tractor had no rollover protective structure (ROPS). The farmer's younger son, age 10, was riding on the tractor. He was pinned beneath the tractor by his right arm which was severely crushed. The emergency crew lifted the tractor off the boy and rushed him to the hospital. His father was dead at the scene.

\section{Overview}

Deaths involving tractors contribute to agriculture having one of the highest on-the-job annual death rates -20.3 deaths for 100,000 workers nationally. That statistic from 1997 has been virtually unchanged for many years. In a 1999 study conducted by the Deep-South Center for Agricultural Health and Safety, it was found that, on average, 21 adults died each year in Florida agriculture in recent years. At least 74 of those deaths involved machinery, including tractors overturning and crushing their drivers. Across the nation, approximately 36 per cent of the agricultural work fatalities in 1997 involved a tractor, and 19 percent involved other machinery, according to the National Safety Council.

Safer tractor operations and the use of protective equipment could prevent many of the deaths and injuries involving tractors. Farm and ranch owners and tractor operators play a major role in making tractor operations safer. Owners have responsibilities for providing a safer environment and safer equipment. They also coordinate maintenance designed to ensure the safety of the equipment. The final responsibility for making the operation of tractors safer lies with the tractor operators themselves.

It's often only when an incident occurs that people become focused on what might have prevented injury or loss of life. The following pages give guidance about how everyone in their operation can work together to make using tractors safer.

This publication is one in a series of UF/IFAS Extension circulars devoted to tractor safety for various audiences. The complete series is (also see the Resources section at the end of this publication):
- Safer Tractor Operations for Agricultural Employers (CIR 1249)

- Safer Tractor Operations for Privately Owned and Operated Farms and Ranches (CIR 1250)

- Safer Tractor Operations for Home and Acreage Owners (CIR 1251)

- Safer Tractor Operations for Landscape Maintenance/Horticultural Industries (CIR 1252)

- Safer Tractor Operations for Emergency and Rescue Personnel (CIR 1253)

- Safer Tractor Operations for Farm Workers/Employees (CIR 1254)

\section{Foundations of Tractor Safety: Safer Operations on Safer Tractors in Safer Environments}

The three major elements which must be considered when developing programs to make tractor operations safer are:

- the tractor operator,

- the tractor, and

- the environment.

We have control over some aspects of these elements; for example, setting up fields so that there is adequate turning room at the ends of rows is a safety factor entirely within human control, so is the speed at which the tractor is operated, as well as if a rollover protective structure (ROPS) and seat belt are used. However, there are elements over which we have no control. In those cases, operations must be modified in order to complete the job safely.

Deaths and injuries result from hazards. A particular driver may be safety-conscious and driving a tractor equipped with safety features, yet he/she might drive into a hazardous environment with a false sense of security; or because an environment is considered "safe", an operator might tolerate an unsafe tractor. Either of these situations is likely to result in an incident. Preventing incidents means 
recognizing hazards and avoiding them or, at least, taking appropriate precautions if they must be encountered.

An operator who uses good safety practices on a tractor with safety features reduces the chances of being killed or injured.

\section{A. A Safer Operator}

The Federal Labor Standards Act requires that individuals operating a tractor with more than 20 PTO horsepower must be at least 16 years old, except under the following conditions:

A 14- or 15-year-old may operate a tractor as a student in a bona fide agricultural education program or if he/she has received a certificate of completion from a 4-H Federal Extension Service Training Program or a U.S. Office of Education Vocational Agriculture Training Program.

Youths of any age can be employed by their parents to work on a farm they own or operate. However, remember the exemption does not eliminate the hazard.

The following rules apply to all tractor operators employed in agribusinesses under the jurisdiction of the Occupational Safety and Health Act (OSHA). Although these rules do not govern everyone, they should be applied to all tractor drivers.

- If the tractor has a ROPS, securely fasten the seat belt. Do not use seat belts on tractors that don't have ROPS.

- Where possible, avoid operating the tractor near ditches, embankments, and holes.

- Reduce speed when turning and crossing slopes and on rough, slick, or muddy surfaces.

- Stay off slopes that are too steep for safe operation.

- Watch carefully for obstacles and other hazards in the tractor's path, especially at the end of rows, on roads, around trees and in other blind corners.
- The only person on a tractor should be the operator, unless the operation requires a rider, as in the case of transplanters and harvesters, or for instruction, if there is a built-in instructional seat available. For more information, see the section on Dangers of Extra Riders.

- Operate the tractor smoothly, avoiding jerky turns, starts, or stops.

- Hitch only to the drawbar and hitch points that the manufacturer recommends.

- When the tractor is stopped, set the brakes securely and use park lock, if the tractor is equipped with it.

- Lower hydraulic equipment. If hydraulic lines lose pressure, raised equipment lowers suddenly, crushing anything -- or anyone -- underneath.

- Only authorized personnel should be permitted to operate a tractor.

- The tractor operator has the responsibility to be aware of other workers and machines and to not endanger them.

- Common hand signals should be used to communicate with others in the area.

\section{More Tractor Operator Tips}

- Never dismount from a tractor when the engine is running, unless the operation requires it.

- Properly mount and dismount from the tractor; slips and falls cause many injuries.

- Don't consume alcohol or drugs, including medications that may impair judgement, during work hours or for four hours before starting work.

- Use hearing protection.

- Headaches can be a sign of carbon monoxide hazards. Check to see if the exhaust is in a location that exposes the operator to exhaust fumes. There have been instances of carbon monoxide exposure using an open-station tractor in the field. 


\section{Operator's Responsibilities}

Tractor owners should consider explaining the following responsibilities to anyone who might operate their tractor.

Operators are responsible for daily pre-operational checks of their tractors - even if a shop mechanic has responsibility for servicing it. This pre-operational check needs to include at least the following activities:

- Check oil, fuel, and other fluid levels.

- Check for any oil, fuel or fluid leaks.

- Check tire condition and inflation levels.

- Make sure that platforms and steps are clean and free of debris and tools.

- Check to see that lights, brakes and the steering mechanism are working properly.

- Make sure that all gauges are giving proper readings and that the engine transmission and hydraulic system aren't making any unusual sounds.

A tractor might require additional pre-operation checks. The operator should know what they are and should perform them daily or more frequently. $\mathrm{He} / \mathrm{She}$ can determine which checks are needed by reviewing the maintenance manual for the tractor.

A tractor is not the only "machine" that needs a pre-operation check. The operator does too.

- Is he/she fit to drive?

- Is he/she too sick, tired or angry to drive?

- Does he/she have medications or other substances in their body that might adversely affect judgement, attention, or reaction time?

If the answer is yes to any of these questions, the operator should not drive.

\section{Important Checks}

Operators should conduct a pre-operational check of their clothing.

- Clothing should be comfortable and close fitting, with no loose ends or strings that could easily be caught in moving parts.

- Shoes should have protective steel-tipped toes and skid-resistant soles.

- The condition of any other personal protective equipment the operator is wearing should be checked. It may include a respirator, eye and ear protection, protective clothing, head gear, gloves and boots.

- Keep long hair contained in a cap. Long hair can easily be caught in moving parts, resulting in scalping injuries.

Avoid smoking when fueling the tractor, working around dry materials or when working with pesticides.

The operator should make periodic safety checks throughout the day. Stay alert and remain as comfortable as possible.

- Discomfort can be distracting and tiring.

- Take short breaks frequently.

- Stretch and move around.

- Drink small amounts of non-alcoholic beverages frequently.

- Eat moderately.

- Exhaustion means 'stop working.'

The incident you prevent might well save your life and the lives of others.

\section{Shortcuts are Short-sighted! or, Invest Seconds, Save Lives!}

Stepping over a power takeoff instead of walking around a tractor might seem like a time-saving shortcut, but it exposes you to a much greater risk of injury or death. 
Often, there's a "recommended safe way" of doing a task and then there's another way that seems quicker but is more hazardous. Many people use the more dangerous shortcut to save time.

However, timed studies show that the time invested in doing a task safely is quite insignificant, especially when compared to the costs of injuries or possible death that could result from the extra hazards involved in the shortcut.

Here are some examples of the small amount of time it takes to be safe. To put these times in perspective, the total time invested for 100 repetitions of a task was calculated. Note that 100 repetitions may occur over an entire year/season. For example, stepping over the PTO may take 2 seconds less time than walking around it. So, if this was done 100 times in a season, you would save only 3.33 minutes.

However, every one of those 100 times, you put yourself at risk for injury or death. (See Tables 1 and 2.)

\section{B. A Safer Tractor}

Modern tractors are much safer than tractors of 20 or 30 years ago. Rollover protective structures (ROPS) and seat belts now prevent many deaths and injuries from tractor overturns. Improved hitch designs and weight distribution have made tractors more stable. Improved shielding of power takeoff shafts, improved hydraulic designs, improved brakes, wider wheel bases, better visibility, and other features such as running lights and adjustable seats have also contributed to safer tractors.

Despite modern safety improvements, there are still dangers that come with driving a tractor. These dangers can be reduced if the tractor operator understands the tractor and maintains and operates it properly.

A few modern features, however, have actually increased the potential danger.

- Increased rear axle torque increases the risk of rear overturns.

- Faster tractors increase the danger of side overturns due to centrifugal force on curves or corners.
- Faster tractors increase the danger of losing control during road travel.

Management has the responsibility of providing operators with safer tractors. Consider the following ways to improve tractor safety.

\section{Rollover Protective Structures (ROPS)}

Nearly one half of tractor-related deaths are due to tractor overturns.

The side overturn is the most frequent type of overturn. Studies indicate 75-85 percent of overturns are to the side. A tractor has a high center of gravity, thus, sharp turns and/or high loads can cause it to overturn quite easily - and at relatively low speed. Centrifugal force can cause a tractor to overturn if the direction of travel is changed. For example, when a tractor's right front wheel veers into the road ditch, the natural reaction of the operator is to steer it back onto the roadway, however, the forces will pull the tractor over on its side.

The second type of overturn is to the rear. These overturns may be less frequent, but without a ROPS, they are the most deadly. It is estimated that, without a ROPS, 85 percent of rear overturns result in the operator's death.

Rear overturns occur when the tractor can't move forward and the rear axle torque causes the tractor to pivot around the rear axle. The entire event can happen in as little as 1.5 seconds; the tractor can reach the point of no return in as little as 0.75 seconds. There is no time for the operator to react. Rear overturns are often due to pulling a load uphill, being stuck in the mud, or attempting to pull a load that has been hitched above the drawbar.

When possible, operate a tractor equipped with a rollover protective structure (ROPS). Most tractors should be equipped with a ROPS and seat belt. However, certain tractors are exempt, including:

- Tractors built before October 1976;

- Tractors with less than 20 horsepower; and

- Tractors on which equipment is mounted that would be incompatible with ROPS. 
- Low profile tractors used in groves, farm buildings or greenhouses in which the vertical clearance would interfere with normal operations. However, it is recommended to use tractors with ROPS in these situations since most manufacturers now offer ROPS that fold down when necessary for clearance.

However, exemptions are not to be used as an excuse for not using safety features. If the use of the tractor permits ROPS and seat belts, they need to be provided. An exemption doesn't eliminate hazards.

Always wear a seat belt on a tractor with a ROPS. If an overturn occurs, the seat belt helps keep the driver within the safety zone that the ROPS creates. Seat belts are not to be used on tractors without a ROPS since, in that case, an operator constrained in the seat would be crushed. Without a seat belt, the driver may be thrown around in the cab, which can result in severe injuries or unconsciousness. Either of these could make it impossible for the driver to escape the cab, which could be fatal, especially if the tractor has overturned into a canal.

\section{Frequently Asked Questions about Rollover Protective Structures (ROPS)}

\section{How common are tractor overturn injuries?}

Tractor overturns are the leading cause of work-related deaths in agriculture.

Can overturn injuries be prevented? The use of a ROPS and seat belt is 99 percent effective in preventing deaths and injuries from overturn.

Why is a seat belt needed with the ROPS? The seat belt keeps the operator within the zone of protection in an overturn. A seat belt must not be used on tractors without a ROPS because it will prevent the operator from jumping clear in a dangerous incident.

\section{How do I know if a ROPS is available for my} tractor(s)? The ROPS directory, prepared by the National Farm Medicine Center in Marshfield, Wisc., contains this information The directory is distributed to county extension offices and equipment dealers. Most manufacturers offer ROPS at affordable prices.
Contact your dealer for details. The ROPS directory is available on the Internet at <http://www.marshfieldclinic.org/nfmc/rops/ default.htm>. Or you can check with your local tractor dealer.

I can't afford ROPS for all my tractors, but I want to reduce my risk of being hurt in an overturn. What can I do? Safety can be improved by using a tractor equipped with a ROPS for riskier operations. The value of a ROPS is such that trading in an older tractor for a model equipped with a ROPS might be worth considering. Many farms have at least one tractor with a ROPS. Consider using that tractor for riskier operations.

If ROPS are so great, why can't I make my own? Only ROPS that have been tested to meet specific standards are acceptable. Tractors with ROPS that haven't been approved can split during an overturn. Anything less than an approved ROPS provides a false sense of security. Altering a ROPS by welding something onto it or by drilling holes in it can make it less effective. The dynamic forces that act upon a ROPS during a tractor overturn make it crucial that a ROPS be properly designed, manufactured, and installed. The ROPS and tractor must work together as a system in order to stay together as a unit in the event of an overturn.

Won't a ROPS limit the way I can use my tractor? Few owners actually remove a ROPS because of interference. ROPS that fold down are available for many tractors.

Some of my tractors have cabs. Isn't the ROPS a part of the cab frame? Many older tractors may have what is known as a weather cab, meaning a ROPS is not part of the frame. In an overturn, these cabs can be more deadly since they provide no chance for quick escape, thus increasing the chances of being crushed.

How do I know if the cab on my tractor has a ROPS as part of its structure? Look for a label indicating it has an OSHA-approved ROPS; most tractors manufactured after 1976 should have these labels. However, labels are not located in a uniform spot, and the cab may cover them up. Look for a seat 
belt. Manufacturers only install seat belts on

ROPS-equipped tractors. Consult the dealer.

\section{More Tractor Safety Tips}

- When a tractor has adjustable wheel widths, operate it with the widest wheel adjustment that is practical for the task at hand.

- Add weights to the tractor to make it more stable.

- Check that shields for the power takeoff and other moving parts are in place and are in good condition.

- Check the brakes individually and then check the brakes locked together with the tractor operating at a transport speed to ensure it will stop in a straight line.

- Inspect the condition and fit of hydraulic lines. Sudden failure of hydraulics could result in loss of control of the tractor or equipment. Also, serious injury could result from being sprayed with hot, high-pressure hydraulic fluid. Check for holes by holding a piece of cardboard above the hoses. Keep hands clear of hydraulic leaks; using the hand can result in serious burns or in hydraulic fluid being injected directly into the hand.

- Be sure that running lights are properly mounted, clean and visible. Two headlights and two taillights, both widely spaced, should be visible to other traffic.

- Mount the slow-moving vehicle (SMV) emblem in the center of the rear of all tractors and machinery that will be used on public roads. The emblem indicates that the vehicle travels at less than 25 miles per hour. The bottom edges of the emblem should be no higher than six feet off the ground.

- Always clean the SMV emblem before entering a public road. Dust and dirt greatly decrease its reflective ability.

- Replace the SMV emblem if it begins to fade.
- Mount a fire extinguisher with an ABC rating on all tractors.

- Mount a dust-proof and waterproof first aid kit on all tractors.

- If tractors are used in dusty conditions or for applying pesticides, equip them with cabs that provide filtered air. Check what the filter is designed to do. The operator must have personal protective equipment in the cab in case he/she must leave the tractor.

- Perform pre-operational checks daily, following the guidelines within the operator's manual.

- Avoid bypass starting.

\section{Bypass Starting Dangers}

Shortcuts are common in agriculture, but they are dangerous. Bypass starting is a very dangerous shortcut.

The term "bypass starting" points to its danger. It bypasses all the safety-start and neutral-start switches in the tractor's electrical and hydraulic systems. The problem comes when someone tries to bypass-start a tractor or other piece of equipment that is in gear. The person can then get pulled down by the drive wheel and be crushed. The runaway tractor can also injure or kill others in the area.

Often operators or mechanics bypass-start an engine because of a maintenance problem with the tractor's neutral-start switch. It's a good idea to immediately repair mechanical problems that might make bypass starting tempting. Remember, every death or injury due to bypass starting could have been avoided.

\section{Safety Switch Check}

Periodically check switches to make sure they are in working condition. This helps avoid the temptation of trying to bypass-start an engine. Following the steps below only takes a few seconds.

- Make sure that no one is standing near the tractor and that no obstructions are around it. 
- Depress the clutch and brake pedals. Attempt to start the engine with gears disengaged and the PTO in neutral.

- Depress the clutch and brake pedals. Attempt to start the tractor with the gears engaged and the PTO in neutral. The starter should not engage.

- Depress the clutch and brake pedal. Attempt to start the tractor with the gears in neutral and the PTO engaged. Again, the starter should not engage.

- On tractors equipped with clutch-mounted start switches, depress the brake pedal but not the clutch pedal. Place the transmission and PTO in neutral, the starter should not engage.

- If either switch is malfunctioning, replace it before further use. See the dealer for parts or service.

- Talk to the dealer about getting decals to apply to farm machinery that warns about the dangers of bypass starting. Such decals act as a frequent reminder to operators.

\section{A Safer Environment}

Tractor overturns in canals, ditches and washouts are common. The steep slopes and loose soils in these environments are serious hazards. Other hazards are found on public roads, blind corners, narrow bridges, culverts, sharp turns, steep terrain and slippery surfaces.

Inspect the environment in which tractors will be used. Identify the hazards and take action to eliminate them. Implement the following suggestions to reduce the environmental hazards:

- Increase the turning area at the ends of rows. Give the tractor operator room for safe turns without coming too close to ditches and canals.

- Move field roads farther from canals and ditches. Equipment needs to be kept behind the shear line of the soil and embankment. The minimum distance recommended for operating machinery near embankments is a $1: 1$ ratio to the depth of the embankment. In other words, the tractor should be no closer to the edge than the depth of the embankment. Following this recommendation prevents bank collapse that can cause tractors to overturn thus crushing operators or drowning them in canals. This distance increases with adverse soil conditions such as sandy or wet soil.

- Control vegetation that can hide hazards. Clearly mark the location of canals, ditches, and other hazards.

- Maintain field roads.

- Widen narrow roads and bridges (where practical).

- Eliminate sharp, blind corners or curves, and rough or slippery surfaces.

- If travel on public roads is absolutely necessary, travel when vehicle traffic is light and visibility is good.

- Use proper marking and lighting on all tractors and attached equipment.

- Prune hedges or trees to improve visibility and reduce the danger of incidents caused by tree limbs hitting the operator.

- Remove tree stumps and other field obstacles.

- Conduct walk-through inspections for washouts before beginning tractor operations. Clearly mark or fill washouts.

- Inspect the farmstead and machinery storage and service area.

- Correct dangerous traffic patterns around hazards.

- Be aware of the location of overhead power lines, especially when towing equipment that may have high points, such as boom sprayers. 


\section{Safer Tractor Operations}

\section{A. Dangers of Extra Riders}

\section{Tractor Runover Kills Girl}

Janice, a 5-year-old, died after she was run over by the massive rear wheel of a 9-ton tractor she had been riding alongside her father. She was airlifted to a nearby hospital and rushed to the emergency room, but she died before she made it into surgery.

Janice was riding on the side of a tractor her father was driving. After going down a short hill, the tractor hit a bump and threw the girl off her perch, outside the tractor's cab.

Janice's father, Adam, was unable to stop the tractor. The back left tire, which measured about 5 feet in diameter and weighed an estimated 1,500 pounds, crushed the girl's head. Adam carried his daughter into the house's downstairs bathroom, then told his wife to call for an ambulance.

\section{Why Take the Risk?}

Tractors are not passenger vehicles. Except for those built with instructional seats, they are designed for one person to operate.

Passengers on tractors can interfere with safe operation of a tractor. The extra rider can distract the operator, block access to controls or obstruct the operator's vision.

Tractors (except those with instructional seats) are designed to provide protection for only one person, the operator. All tractors manufactured since 1976 have a special rollover protective structure -- a ROPS -- that provides a safe environment for the operator if the tractor overturns. The use of the seat belts on tractors with ROPS will protect the operator from serious injuries.

Extra riders have no such protection. There is no safe environment for extra riders on tractors. Older model tractors without ROPS offer no overturn protection for operators or extra riders.

Many people have the mistaken idea that enclosed cabs protect extra riders. This notion only gives tractor operators a false sense of security. Many tractor runover deaths happen when a person, often a child, falls out of an enclosed cab. An enclosed cab can reduce the chance that a rider will be bumped off a tractor, but it can't eliminate the risk. The small measure of protection from an enclosed cab is not a guarantee of safety for extra riders. Door latches may not be fully latched; latches can be bumped; and children can become restless and tamper with latches and controls. Note: Tractor models with instructional seats are limited to cab tractors.

\section{Causes of Runovers}

There are many reasons why extra riders are thrown from the tractor, frequently resulting in death. These include:

- Sudden stops

- Driving over holes, stumps and debris; or

- A sharp turn causes the extra rider to lose his or her footing or to be tossed off the tractor. The tractor does not have to overturn for an extra rider to be thrown from the vehicle.

Operators may think they can respond quickly and stop the tractor if something occurs, especially if the tractor is moving very slowly or if only simple tasks are being performed. The most common comment from people involved in tractor runovers is how quickly the incident occurred (see Table 3).

Runovers can also occur when the tractor is involved in an incident. One common scene occurs when a rider is thrown after the tractor hits a building, bridge, or another vehicle. If the tractor overturns, the operator and the rider are both in danger.

\section{The "No Riders" Rule}

The only way to prevent extra rider injuries or deaths is to prohibit riders on tractors except for those actually involved in training on a tractor equipped with an instructional seat. Consider making a permanent policy for not allowing riders on tractors.

Make sure all tractor operators observe the "NO RIDERS" rule. Discuss the importance of this rule with managers and employees. It's also helpful to 
post "NO RIDERS" decals on all tractors to remind others about the policy. "NO RIDERS" decals may be purchased from the Farm Safety 4 Just Kids organization (1-800-423-5437). Many implement dealerships also carry these decals.

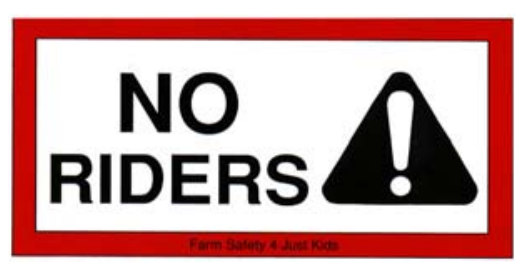

"No Riders" Decal.

The most effective way to observe the NO RIDERS" rule is to eliminate the need for extra riders on tractors. Use other vehicles, such as trucks or motor vehicles, when transporting people to fields or distant work sites. Here are some tips:

- Discuss with family members why a "NO RIDERS" rule is important.

- Make sure all guests know the owner's opinion about extra riders.

\section{Problems on Other Equipment}

Other farm equipment may be unsafe for extra riders, too. Most all-terrain vehicles, skid steer loaders, and riding lawnmowers are designed for one person.

Some combines and other equipment have extra seats. Seats for extra riders should be added only by the manufacturer because many factors are considered in designing them for safety. A makeshift seat added to farm equipment cannot ensure safety.

Enforcing a "NO RIDERS" rule may be the single most important action in protecting people on farms or ranches. The rule may challenge years of tradition, but it provides a safer way to pass on the agricultural heritage.

\section{B. Road Safety for Tractors and Farm Machinery}

Each year, incidents involving tractors and other farm machinery occur on public roads, causing deaths, injuries, and costly equipment damage.
Collisions with other vehicles make up nearly half of these incidents. Running off the road, overturning, striking a fixed object or the operator falling off the equipment make up the remainder.

About one-third of tractor-related deaths occur on public roads, according to the National Safety Council. Many people assume that these collisions happen during bad weather or hazardous conditions. Studies have repeatedly shown that nearly 80 percent of tractor-motor vehicle collisions occur on dry, straight roads in daylight.

Here are some practical tips that can help. Although most of these points may seem obvious, they are nonetheless important to review.

- Keep travel on public roads to a minimum.

- Travel on public roads when traffic is at a minimum and visibility is good.

- Avoid moving tractors and other farm equipment on public roads between sunset and sunrise, when visibility is 500 feet or less or when rain makes roads hazardous.

- Consider using trailers to transport tractors and equipment to distant fields and other locations.

- Be thoroughly familiar with how to operate the tractor and any equipment being towed.

- Obey all traffic laws, including speed limits, traffic signals, and signs.

- Have slow-moving vehicle emblems (required for vehicles traveling $25 \mathrm{mph}$ or less) and reflectors in place on all tractors and implements and make sure that they are clean and in good condition. New technology has improved the visibility of the slow-moving vehicle emblem. The emblem is made of two materials - a fluorescent material for daytime visibility and a reflective outline for nighttime. In the past, slow-moving vehicle emblems tended to fade excessively. Emblems made with the new material are more expensive than emblems without it, but their longevity offsets the extra cost. Reflective tape is also useful to increase the visibility of your tractor and equipment. Experts recommend applying it to the front, back, and 
sides of equipment. (See "Lighting and Marking -- Summary of ASAE Standard S279.10" below for more details.)

- Make sure that brake pedals are locked together and that brakes are adjusted for equal pedal movement. This helps ensure that the tractor will stop in a straight line.

- Since tractor brakes have limited holding power, use low gears whenever taking heavy loads up or down hills.

- Properly light tractors and equipment. Lighting should include turn signals, headlights and taillights.

- Check to see if all lights are working, and use them if there is any question about visibility.

- Keep flashing amber lights on when operating farm equipment on public roads.

- Turn off any work lights that face the rear. Make sure the load does not obscure lights and warning devices. If night driving is necessary, clean headlights and taillights.

\section{Common Causes of Collisions}

Nearly half of all collisions between motorists and farm implements involve one of two scenarios The left-turn collision or the rear-end collision. The number of incidents involving each scenario is about equal.

\section{a. Left-Turn Collision}

The scenario: The left-turn collision occurs when the tractor is about to make a left turn at the same time that a motorist tries to pass.

Why it happens: Like drivers of semi-tractor-trailers, tractors sometimes need to make wide left turns. Drivers may swing the tractor wide to the right before making a left turn because they need extra room to line up with a farm gate or driveway. Motorists may find this maneuver confusing, especially if they think that the tractor operator is moving over to let them pass. Tractor operators may be unaware of the hazard to a following motorist, especially when the tractor is towing equipment, because tractor drivers then have limited visibility and may not see the motor vehicle at all.

How to avoid: Tractor operators can reduce the potential for the left-turn collision by installing extension mirrors on the tractor to improve visibility. A sticker that is often seen on semi-tractor-trailers is a good reminder to motorists: "If you can't see my mirrors, I can't see you." This sticker can be placed on farm equipment to provide motorists with more information.

\section{b. Rear-End Collision}

The scenario: The rear-end collision happens because a motorist doesn't see the farm machinery in time.

Why it happens: It's easy to misjudge speed when approaching a slow-moving vehicle. In most cases, there are only a few seconds to react and slow down. For example, if the motorist is driving 55 miles per hour and comes upon a tractor that's moving 15 miles per hour, it only takes five seconds to close a gap the length of a football field.

Another way of looking at it: If the driver of a motor vehicle that is traveling at 50 miles per hour spots a tractor 400 feet ahead on the road and the tractor is moving at 20 miles per hour, the motorist has less than 10 seconds to avoid a rear-end collision.

In those ten seconds, the motorist must recognize that a dangerous situation exists, determine the speed at which the tractor is moving, decide what action to take and apply the brakes hard enough and long enough to avoid a collision.

How to avoid: Use marking and lighting (as described in section 4) to provide motorists with the information they need to recognize the hazard.

\section{c. Sideswipe Collision}

The scenario: When a motor vehicle meets or attempts to pass a farm vehicle, it is sideswiped by the tractor/equipment.

Why it happens: Some farm operators haul equipment that is extra wide or especially long, but 
some motorists do not take into account the width or length of the equipment or the sway of the tractor and implement. Also, equipment takes up more available roadway when approaching bridges, mailboxes, or other shoulder obstructions.

How to avoid: In order for oncoming and passing traffic to better assess the width of farm equipment, reflective tape and materials should be used to mark the extreme front and rear points of the machine.

\section{d. Head-On Collision with Other Motor Vehicle}

The scenario: While a motor vehicle is passing a farm vehicle, it is confronted by another motor vehicle approaching head on. There is no time to get off the road and a head-on collision occurs.

Why it happens: As in the Sideswipe, a driver may fail to appreciate the length of the farm equipment to be passed and be forced to spend a longer time in the passing lane. Add to this that the driver's view when preparing to pass may be blocked by the farm equipment.

\section{e. Head-On Collision with Vehicles}

The scenario: An on-coming motorist collides head-on with the towed implement that is wider than the tractor.

Why it happens: Wide equipment poses a special hazard, especially at night, because oncoming traffic does not realize that the tractor is pulling equipment that extends across the centerline and into the opposite lane of traffic until it is too late to react.

How to avoid: If at all possible, keep road travel of wide equipment to a minimum, especially at night. Equipment that is well-marked and well-lit will provide motorists with better information to help them react in time. Reflective materials should be used to mark the extreme front points of the machine.

\section{Escort Vehicles}

At times, tractors or the equipment they are pulling cross into the oncoming traffic lane, especially on narrow rural roads. In these situations, consider using an escort vehicle equipped with flashing yellow lights. Remember that equipment can obscure rear tractor lights.

Even if an escort vehicle is not required by law, it is good practice. For large equipment, the local police, sheriff or highway patrol may provide this service.

Escort vehicles are required by state laws under certain conditions. These conditions are listed in Table 4. This table is not definitive. If you have any question about an oversize vehicle Contact your Department of Transportation permits division.

For Florida, additional requirements for the kind of vehicle that may be used as an escort, as well as for its marking and lighting are specified in the Florida Administrative Code (F.A.C.) Section 14-26.0012. Contact your state Department of Transportation for complete details about the kind of vehicle which is acceptable for escort use, as well as the proper marking and lighting of escort vehicles.

\section{Lighting and Marking -- Summary of ASAE Standard S279.10}

Remember the reason for marking and lighting is to provide motorists with better information. Marking and lights that are obscured or not at the motorist's eye level do not provide "quick reflex" information for the motorist.

An excellent example of this principle was the placement of a brake light in the rear window of cars. A study of its effectiveness was conducted among a test group of New York City cab drivers. Placement of the light at the motorist's eye level helped motorists to see brake lights several cars ahead and reduced the number of rear-end collisions by $50 \%$. For the collisions that did occur, damages were reduced by one-third. This happened, not by reforming or changing drivers, but simply by providing them with better information.

What are ASAE Standards? ASAE is the professional society for those interested in engineering knowledge and technology for food and agriculture, and related industries and resources. Standards are based on experience and research, and 
they are developed by committees that include qualified people from producer, consumer, and general interest groups.

This lighting and marking standard applies to all tractors, other self-propelled farm machinery, and towed machinery used for farm operations (for more details see standard ASAE S390.1) which might be driven or towed on any road that is also accessible to the public. Self-propelled machines and towed machines are considered separately in the standard. The following is only a summary of ASAE Standard 279.10 OCT98 "Lighting and Marking of Agricultural Equipment on Highways," consult the standard for exact details about the specific types of lights and their placement.

\section{a. General Recommendations for Lighting Self-Propelled Equipment}

The standard recommends six features related to lighting self-propelled equipment, which includes tractors. The standard defined the proper lateral and vertical placement of lights; in general, lights should be no lower that $3 \mathrm{ft}$ from the ground or more than 10 feet high.

Headlamps. - Two standard headlamps should be mounted at the same height and spaced as far apart as possible, the same distance on either side of the centerline. The standard also defines how bright headlamps should be.

Work lamps. - The equipment should be fitted with work lamps. Rear-facing work lamps should not be used on the highway, but others should be used to illuminate the area near the equipment on its sides and front.

Taillights. - Two red taillights should be mounted at the same height, as far apart as possible, and the same distance on either side of the centerline. Taillights should be at least 3 feet from the ground and not more that ten feet.

Warning Lights. - Extra-wide vehicles (12 ft or more) should have flashing amber lights marking the sides of the vehicle to reduce the danger of sideswipes. The lamps should flash in unison at 60 to 85 times per minute.
Turn Indicators. - In addition to the red taillights, the equipment should carry turn indicators. When a turn indicator is on, the warning light on the side of the flashing turn signal should flash faster, up to 110 flashes per minute, while the warning light on the side opposite the turn should burn steady and not flash.

Seven-terminal Receptacle. - Details of the seven-terminal receptacle, for machines commonly used with equipment, are defined in the standard. Towed equipment needs to have the matching seven-pin plug. The wiring of the plug and receptacle are described in the standard.

\section{b. General Recommendations for Marking Non-self-propelled Equipment}

Marking refers to using reflectors, reflective materials, and specific signs to make the presence and the size of towed equipment obvious to other motorists. The general requirements for marking self-propelled equipment are:

Rear Reflectors - Red reflectors visible to the rear up to a distance of $600 \mathrm{ft}$ should be used to mark the outermost side extensions of the equipment.

Front Reflectors - - Yellow reflectors visible to the front should mark the extreme left and right of equipment, especially if it is wider than the towing machine.

Conspicuity Material -- Two kinds of material visible to the rear should be used: retroreflective' material that means the material or device reflects back to the light source, and red-orange non-reflective, fluorescent material. Conspicuity material visible to the front should be yellow.

Slow-moving Vehicle (SMV) Emblem -- This triangular emblem should be visible to the rear of any slow-moving machinery ( $<25 \mathrm{mph})$. Remember: point up!

If Tractor Illumination Is Obscured - Towed equipment should carry any lighting that it obscures on the tractor. For example, if the towed equipment blocks a tractor's taillights from the view of following motorists, the towed equipment should 
carry taillights. The same is true for the tractor's flashing red warning lights and its turn indicators.

\section{If the Tractor's SMV Emblem Is Obscured -}

The SMV emblem must be visible to following motorists. If the equipment being towed obscures the SMV emblem on the tractor, then one must be mounted on the towed equipment.

\section{c. Special Recommendations for Lighting and Marking Non-self-propelled Equipment}

The non-self-propelled equipment that is towed by tractors should have its own lighting and marking. In many cases, the standard has special recommendations based on the width or length of the towed equipment.

Towed equipment should be marked and lighted so that it is clearly visible from the rear and the side. It is important that the full width and length of the equipment be obvious to motorists who are approaching quickly from the rear, who are trying to pass slow-moving-equipment, or who are approaching as oncoming traffic.

Equipment Width and Length

The following special requirements apply in these situations:

Extra Width: The towed equipment extends:

more than $4 \mathrm{ft}$ to the left of the tractor's centerline, (see 1 below),

more than $4 \mathrm{ft}$ to the right or left of the tractor's centerline (see 2 below), or

more than $6 \mathrm{ft}$ from the centerline in either direction (see 3 below).

Front-Mounted Equipment: The attached equipment is in front of the tractor (see 4 below).

Length: The towed equipment extends:

more than $4 \mathrm{ft}$ behind the hitch point on the tractor (see 5 below),

more than $16 \mathrm{ft}$ behind the hitch point on the tractor (see 6 below), more than $25 \mathrm{ft}$ behind the hitch point on the tractor (see 7 below).

1) The towed equipment extends more than $4 \mathrm{ft}$ to the left of the tractor's centerline.

Special lighting requirements - Covered above under "If Tractor Illumination IsObscured."

Special marking requirements - At least one amber or yellow reflector visible to the front positioned to indicate as nearly as practicable the left projection of the equipment.

2) The towed equipment extends more than $4 \mathrm{ft}$ from the tractor's centerline in either direction.

Special lighting requirements - Covered above under "If Tractor Illumination IsObscured."

Special marking requirements - In addition to the amber or yellow reflector required for equipment that extends more than four feet to the left of the machine centerline, at least two red reflectors visible to the rear and mounted to indicate as nearly as possible the extreme left and right projections of the equipment.

3) The towed equipment is more than $12 \mathrm{ft}$ wide (or extends more than $6 \mathrm{ft}$ from the centerline in either direction).

Special lighting requirements - Extra-wide towed equipment should have flashing amber warning lights visible front and rear, red tail lamps, and turn indicators. The warning lights should flash in unison with the warning lights on the tractor.

Special marking requirements - 1) Visible to the rear: Red retroreflective material and non-reflective red-orange fluorescent material. The retroreflective material should mark the left and right extremes of the equipment. Use enough reflective and non-reflective material so that there are no unmarked gaps of more than $6 \mathrm{ft}$. 2) Visible to the front: Two yellow reflectors as close as possible to the right and left extremes of the equipment.

4) The attached equipment is in front of the tractor. 
Special lighting requirements —None.

Special marking requirements - 1) Visible to the rear: Red retroreflective material and non-reflective red-orange fluorescent material. The retroreflective material should mark the left and right extremes of the equipment. Use enough reflective and non-reflective material so that there are no unmarked gaps of more than $6 \mathrm{ft}$. 2) Visible to the front: Two yellow reflectors as close as possible to the right and left extremes of the equipment.

5) The towed equipment extends more than $4 \mathrm{ft}$ behind the hitch point on the tractor.

Special lighting requirements - Covered above under "If Tractor Illumination IsObscured."

Special marking requirements - This equipment requires an SMV emblem of its own, visible to the rear.

6) The towed equipment extends more than $16 \mathrm{ft}$ behind the hitch point on the tractor.

Special lighting requirements - Covered above under "If Tractor Illumination IsObscured."

Special marking requirements - This equipment requires an SMV emblem of its own, visible to the rear. In addition, the sides of the equipment should be marked with amber or yellow reflectors, spaced every $16 \mathrm{ft}$ maximum. A reflector should be placed as far to the rear on each side as possible.

7) The towed equipment extends more than $25 \mathrm{ft}$ behind the hitch point on the tractor.

Special lighting requirements - This equipment should have its own set of taillights, warning lights and turn indicators as described above.

\section{Loading and Towing}

\section{Towing Equipment}

- Make sure that the tractor is properly counterweighted and that all attachments are secure and properly mounted.

- Avoid operating attachments during road travel, and keep the power-takeoff lever in neutral.
- Make sure that the tractor is large enough to handle its load and hitch the load only to the tractor's drawbar hitch points. The drawbar is designed for pulling heavy loads without the risk of a backward overturn. If the load is hitched any higher, the tractor can overturn quickly by rotating around the rear axle.

-When towing equipment without brakes, keep speed under 20 miles per hour.

- Towed equipment should have brakes if, when fully loaded, it weighs more than one and a half times the weight of the towing unit. Stopping distances increase with speed and as the weight of towed loads increases, as well as on hills and slopes.

- When towing equipment with brakes, stay below 25 miles per hour.

- Equipment that weighs more that 4.5 times the weight of the towing unit should not be towed.

\section{Front-End Loaders}

Front-end loaders can make tractors unstable and subject to side overturns.

-When using a tractor with a front-end loader, use the wide wheel settings and add rear weights as needed.

- Travel with the bucket in a low position and at low speeds, especially when turning or traveling on rough and slippery terrain.

- Avoid fast starts and stops.

\section{Loading and Unloading Tractors}

When loading a tractor onto a trailer or truck, always load it on level, stable ground. Make sure that the truck or trailer cannot move by setting the brakes or blocking the wheels or both. Whenever possible, slowly back the tractor onto the truck or trailer. Check to see if anyone is behind the tractor or near the trailer during loading.

- Make sure ramps are clear of mud, grease, or debris. Make sure they are secure. 
- Lock the brakes on the tractor and secure it to the trailer with chains and load binders.

- Fasten chains and lock and wire load binders so that they can open.

- If possible, someone nearby should guide the tractor operator with hand signals.

- Check the owner's manual for specific recommendations.

\section{Miscellaneous Topics}

\section{A. Other Tips for Maneuvering}

- Slow down on turns and curves. A tractor's turning radius is much smaller than an automobile's. Taking a curve too fast can cause an overturn or a jackknife, if machinery is attached.

- Make sure that maneuvers when entering, turning, or leaving the highway don't interfere with other traffic.

- Keep in mind that towed equipment might swing into the oncoming lane.

- Only use the road shoulders when they are stable and well-maintained. Using unstable edges and shoulders can cause a tractor to overturn. Also, driving along the edge can be misleading to motorists. They may pull out to pass just as the tractor re-enters the roadway to avoid a mailbox or bridge. Remember that many motorists aren't familiar with tractors or equipment.

- To let a line of cars pass, pull over to the side and stop, otherwise a culvert, mailbox, or other hazard might force the tractor to re-enter the roadway while cars are still passing.

\section{B. Hazards of Filling Gas Cans}

Vehicle fires sometimes occur while people are filling metal gas cans placed on plastic surfaces. This type of fire usually involves a gas can in the back of a pick-up truck with a plastic bed liner.

Gasoline tends to carry a static electric charge. When pouring gasoline into a can, this charge can build up on the can. If the can is sitting on concrete or on the ground, the static charge can safely flow away. But when the can is sitting on plastic, such as the plastic bed liner in a truck, the static charge can not escape because the palstic is an insulator, that is, it does not conduct electricity. A spark can occur between the can and the fuel nozzle and ignite the gasoline.

When the spark occurs in the flammable range in the gasoline vapor space near the open mouth of the gas can, a fire occurs.

Use only gas cans approved by OSHA and follow these precautions.

- Use only an approved container.

- Don't fill any container while it's inside a vehicle.

- Always place the container to be filled on the ground and away from other people and traffic.

- Keep the nozzle in contact with the can while filling.

- Never use a latch-open device to fill a portable container.

- Don't smoke.

- While transporting containers, tie them in place.

\section{Steep Slopes}

Sometimes a tractor must be operated on a steep slope.

- Backing up or driving down slopes can help prevent rear overturns.

- If a tractor must be operated across the slope, use the widest possible wheel adjustment, very slow speeds and extra caution in watching for obstacles that the wheels might hit.

- Turn the front wheels downhill at the first indication that the tractor may be becoming unstable. 


\section{What to Do When the Tractor Gets Stuck}

Getting stuck is not only embarrassing, but it can also be dangerous.

- Always try to back out. Trying to drive forward is dangerous and can result in a rear overturn.

- If backing out isn't possible, get towed out forward by hitching to the tractor frame.

- If the tractor must be towed out backward, hitch only to the drawbar.

- When towing, use a chain or steel cable and tighten it slowly. Do not use a nylon rope because it can stretch and break, then snap back, resulting in serious injury or death. These have snapped back throwing the cable hook through the cab window, killing the operator.

- Often, someone who is nearby and may be a relatively inexperienced operator is called upon to assist in pulling out stuck equipment. The tractor doing the pulling is actually doing the riskier operation, which could very quickly result in a rear overturn.

\section{E. Used Equipment}

The condition of equipment sold at auctions or transferred from person to person varies widely, so it's important to examine used equipment carefully.

When equipment is purchased through a dealership, the purchase usually includes a warranty, directions for maintenance and operation, warning, "seals of approval" and assurances that the equipment conforms with voluntary or federal standards.

Regardless of where equipment is bought, look for items that may detract from safety, such as missing shields and poor upkeep.

A bargain price may not be worth the risks involved. Don't be blinded by a "sale" and end up with below-standard equipment.

Consider the following questions when buying used equipment.
- Are operating manuals included?

- Are shields and guards in place?

- Is the equipment in decent condition?

Breakdowns due to poor maintenance could cause unsafe working conditions.

- If buying a tractor, is it equipped with a ROPS?

If it isn't, determine who's responsible for paying for and making sure it's installed.

Remember, tractors manufactured after October 1976 that are used by employees are required to have ROPS and seat belts per OSHA Standard 1928.51 (Roll-over protective structures (ROPS) for tractors used in agricultural operations).

\section{F. Hand Signals}

Hand signals have been developed to provide a uniform means of communication between workers on the ground and equipment operators. They are especially useful when noise, distance, or language barriers make voice communication difficult.

There are eleven recognized hand signals found in ASAE Standard S351. They are illustrated in figures on the next two pages of this publication.

1) Come to me.

2) Move toward me.

3) Move out.

4) Start the engine.

5) Stop the engine.

6) This far to go.

7) Stop.

8) Speed up.

9) Slow down.

10) Lower equipment.

11) Raise equipment. 


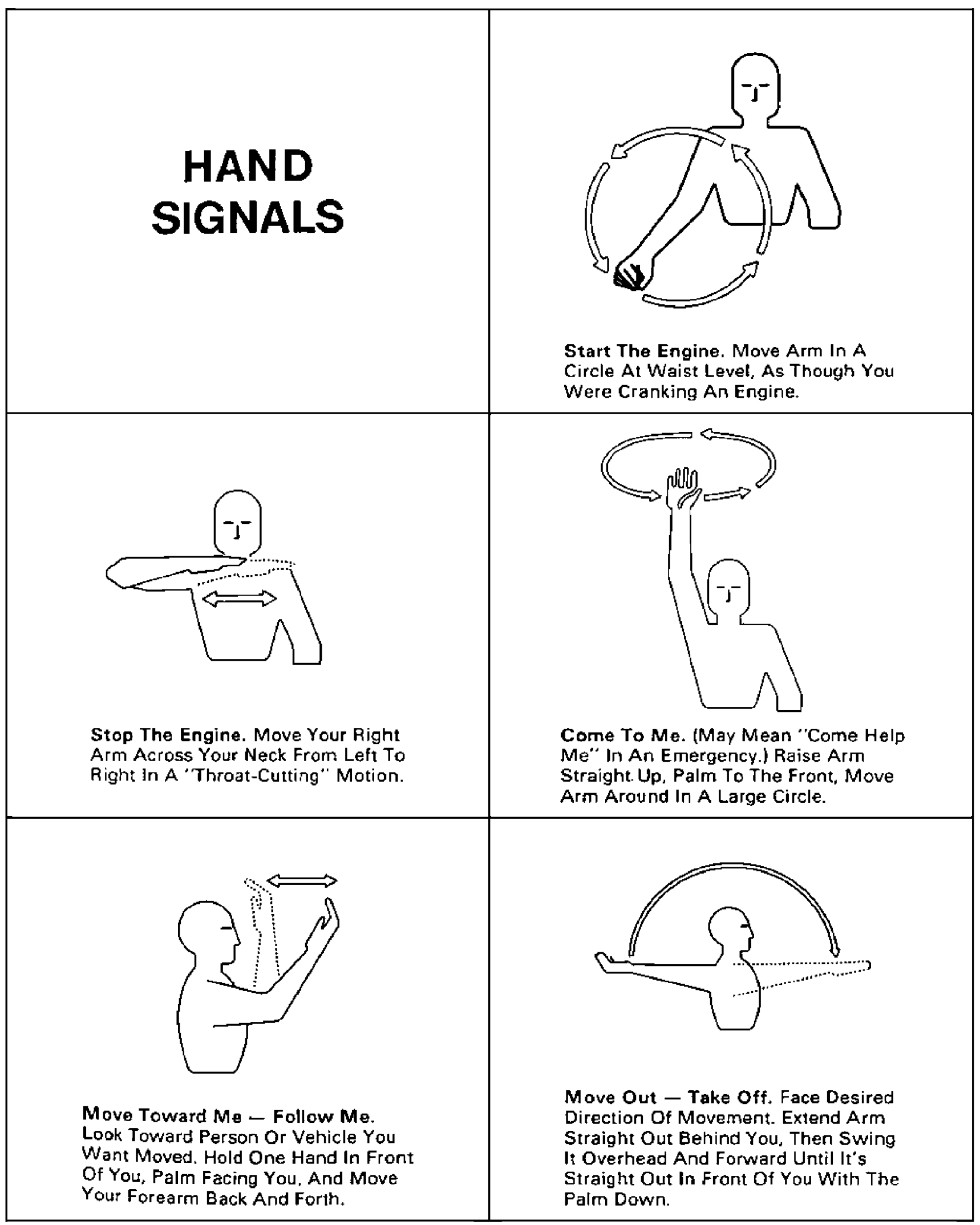

Hand Signals for Communicating with Machinery Operators (Part 1). 


\section{Tractor Operator Checklist}

An operator checklist is provided at the end of this publication (see Table 5). This checklist is designed so that it can be kept as a record of a tractor operator's training.

Safe and competent tractor operators are important to agriculture. Incidents that cause injury and death and damage tractors, equipment or crops are costly.

The checklist can be used as is, or it may be modified to better meet your specific needs. If a service mechanic is responsible for some of the maintenance functions, you might not need them listed on a checklist for your tractor operators.

\section{How Much Do You Know? Pre-Post Test on Tractor Safety}

Testing operators before and after presenting the information in this publication can make their learning efforts more successful. You can use the sample Pre-Post Test as it is, or you may wish to make up your own custom test which covers a specific area in detail or to provide new questions.

We recommend that your Pre-Post Test include no more than ten or fifteen questions.

\section{Sample Pre-Post Test}

A copy of the sample test without the answer key can be found at the end of this publication in Table 7 .

1.Most injuries to tractor operators are preventable. True or False.

2.The safety features on modern tractors can protect the operator from anything. True or False.

3.Shortcuts usually save very little time while increasing danger to the operator. True or False.

4. A ROPS will prevent a tractor overturn. True or False.

5.How often should oil, fuel, and other fluid levels be checked?
6.Discomfort is: A) A normal part of work which keeps the operator alert and makes him work harder, or B) Something that tires and distracts the operator and can make work less safe.

7.Extra riders on tractors are often injured in what way?

8.At what level should warning lights be placed on tractors and other equipment for operation on public roads? A) As low as possible, B) Motorist's eye level, C) as high as possible.

9.The majority of tractor-automobile collisions occur: A) during wet weather, B) at night, C) on dry days in broad daylight.

10.The faster you are driving the less likely you are to jackknife. True or False.

Answers - 1. True; 2. False; 3. True; 4. False; 5. Daily; 6. B; 7. Fall off tractor and are run over; 8 . B; 9. C; 10. False.

\section{Additional Pre-Post Test Questions}

1.Loose clothing is a special danger near a PTO. True or False. (True)

2.Agriculture-related injuries are often made worse because injured workers in isolated areas may have to wait a long time for help. True or False. (True)

3.A seat belt will hold you in the "zone of protection" provided by a ROPS. True or False. (True)

4.Seat belts are not needed for short drives. True or False. (False)

5.Over half of agricultural fatalities result from operating what device? (Tractors)

6.Most injuries to tractor operators are preventable. True or False. (True)

7.It is better to think about safety: A) before an incident, B) after an incident. (A)

8. What are the three major elements to consider in developing safer tractor operations? (The environment, the tractor, and the tractor operator) 
9. When we can not control the environment, greater safety results from modifying our___? (Operations)

10.The safety features on modern tractors can protect the operator from anything. True or False. (False)

11. What is the recommended minimum distance from an embankment to operate machinery? (A distance equal to the depth of the embankment is the minimum recommended distance.)

12.Wet or sandy soil makes an embankment more dangerous. True or False. (True)

13.What does ROPS stand for? (Roll-over protective structure)

14. A ROPS will prevent a tractor overturn. True or False. (False)

15.Increased tractor power makes what dangers more likely? (Rear overturns, side overturns, loss of control)

16.Always wear a seat belt when operating a tractor equipped with a ROPS. True or False. (True)

17.Wide wheel adjustments make a tractor safer to operate. True or False. (True)

18.Never check for a hydraulic leak with what? (Your hand)

19.Shortcuts usually save very little time while increasing danger to the operator. True or False. (True)

20. When possible, making one operator responsible for a tractor is the best system. True or False. (True)

21.What is the minimum age at which employees may operate a tractor? (16)

22. When a tractor is not in use, any hydraulic equipment attached to it should be in what position? (Lowered)

23. What symptom can indicate exposure to carbon monoxide? (Headache)
24.Supervisors have the responsibility of seeing that all tractor operators have a complete understanding of all instructions and rules. True or False. (True)

25.Small rewards -- such as a meal, a local merchant gift certificate, or cash bonus -- presented monthly, can be effective in promoting safety. True or False. (True)

26.Slow-moving vehicle emblems are to be used for equipment traveling less than mph. (25)

27.How often should you check oil, fuel, and other fluid levels? (Daily)

28.How often should you check for any oil, fuel or fluid leaks? (Daily)

29.How often should you check tire condition and inflation levels? (Daily)

30.How often should you check that platforms and steps are clean and free of debris and tools? (Daily)

31.How often should you check to see that lights, brakes and the steering mechanism are working properly? (Daily)

32.How often should you check that all gauges are giving proper readings and that the engine, transmission, and hydraulic system aren't making any unusual sounds? (Daily)

33. How can you determine what special pre-operation checks a tractor might require? (Review the maintenance manual for the tractor.)

34. When you're angry, you should not operate a tractor. True or False. (True)

35.List personal protective equipment that might be needed when operating a tractor. (Respirator, eye and ear protection, protective clothing, head gear, gloves and boots)

36.Smoking is dangerous around what materials? (Gasoline or other fuels, as when fueling the tractor; dry materials; or pesticides) 
37.Discomfort is: A) A normal part of work which keeps the operator alert and makes him work harder, or B) Something that tires and distracts the operator and can make work less safe. (B)

38. When you are exhausted, you should: A) Push through to get the job done, or B) Stop working until you are rested. (B)

39.Impatience promotes: A) Productivity, or B) Dangerous work habits. (B)

40.Dangerous work habits can result in injury to more than the operator. True or False. (True)

41.The few extra seconds taken to do a job safely are: A) more or B) less than the time taken to recover from an injury. (B)

42.Extra riders on tractors are often injured in what way? (They fall off tractor and are run over.)

43.If you've done something many times without incident, it must not be dangerous. True or False. (False)

44.A ROPS makes a tractor safer for an extra rider. True or False. (False)

45.It is easier to fall out of an enclosed cab than most people think. True or False. (True)

46. What is the stopping distance for a tractor going 10 miles per hour, under ideal conditions? (30 ft.)

47.Tradition is the best guide to safe practice. True or False. (False)

48.According to the National Safety Council, what percentage of tractor-related deaths occur on public roads? (1/3)

49. What time of day is best for moving tractors and equipment on public roads: a) daytime, when visibility is good, or b) nighttime when traffic is likely to be less. (A)

50.Correct marking and lighting of tractors and other farm equipment are very important when these vehicles must operate on public roads. What is the most basic required marking device required for public road travel? (SMV or Slow-moving vehicle emblem)

51. What marking device is recommended for application to all sides of equipment for public road travel? (Reflective tape)

52.At what level should warning lights be placed on tractors and other equipment for operation on public roads? (Eye level of motorists)

53.Tractor brakes are capable of stopping a tractor under all circumstances? True or False (False)

54.Name a common road condition where traveling in a low gear makes braking more effective? (Traveling up or down hills)

55.An escort vehicle may be required by law if a tractor together with any towed equipment is excessively A) wide, B) Long C) High D) Any of the above. (D)

56.In Florida, State law specifies what vehicles may be used as escorts. True or False. (True)

57. What simple precaution can make lighting on tractors and equipment more effective? (Cleaning)

58.A motorist may try to pass your tractor just when you are preparing to turn left. What action on your part might encourage a motorist to make this mistake? (Swinging to the right to make a wide left turn)

59.How can the classic "Left-turn collision" scenario be avoided? (Installation of extension mirrors and using turn signals)

60.The majority of tractor-automobile collisions occur: A) during wet weather, B) at night, C) on dry days in broad daylight. (C)

61.As a rule of thumb, what is the maximum weight a tractor may tow? (Up to 4.5 times its own weight)

62.Towed loads which are hitched above a tractor's drawbar can cause what kind of incident? (Rear overturn) 
63.Front-end loaders can make tractors unstable and subject to what kind of incident? (Side overturns)

64.Filling a metal gas can with gasoline increases the static electricity on the can. True or False. (True)

65.The static electricity that builds up on a metal can when it is being filled with gasoline can cause dangerous sparking if the can is sitting on an insulating surface, such as a plastic bed liner. True or False. (True)

66. Long hair is a special danger near a PTO. True or False. (True)

67.The small turning radius of a tractor makes jackknifing more likely. True or False. (True)

68.The faster you are driving the less likely you are to jackknife. True or False. (False)

69.It is generally safer for tractor/ towed equipment combos to drive on the shoulder as much as possible. True or False. (False)

70.Driving your tractor/towed equipment combination on the road shoulder can cause unexpected hazards. True or False. (True)

71.To let a line of cars pass you should: A) simply wave them around, B) pull over into the shoulder and keep moving) or C) pull over and stop. (C)

72.Any metal container is safe for carrying gasoline. True or False. (False)

73. You should always take a second to secure a gasoline container when transporting it. True or False (True)

74.Always keep the nozzle of a gasoline hose in contact with the can while filling. True or False. (True)

75.Using a latch-open device to fill a portable gasoline container can lead to very dangerous spills. True or False. (True)
76.A tractor is more stable on a slope when the front wheels are A) upslope or B) doswnslope from the rear wheels. (Downslope)

77.Driving up a slope in a tractor makes what incident more likely? (Rear overturn)

78.If you sense that the tractor you are operating is becoming unstable, turn the front wheels downhill. True or False. (True)

79.If your tractor gets stuck, what is the first tactic you should try in an effort to get out? (Backing up)

80.Backing up when your tractor is stuck can prevent what incident? (Rear overturn)

81.If backing out a stuck tractor doesn't work, what's the next thing to try? (Tow it out using a front hitch)

82. When pulling a stuck tractor using a rear hitch, to what device on the tractor should you connect? (Drawbar)

83. When towing use only steel cable or chain. True or False. (True)

84.Nylon tow ropes have been known to break when in use, snap back, and kill the tractor operator. True or False. (True)

85. When pulling out stuck equipment, whose job is riskier: A) The operator of the stuck equipment or B) the operator of the tow vehicle? (B)

86. When purchasing used equipment, you usually "get what you pay for"? True or False. (True)

87.Used equipment can literally cost you an arm or a leg because it may lack customary shields and guards. True or False. (True)

88.A tractor cab helps protect the operator from lightning hazards. True or False. (True)

89.It's safe to assume that a tractor operator can operate any kind of tractor. True or False. (False) 
90.It's a good idea to re-certify tractor driver's how often? (Annually)

91.An enclosed cab offers adequate protection for extra riders. True or False. (False)

92. Only children as extra riders are a problem because adults can protect themselves on a tractor. True or False. (False)

93.The following types of farm equipment are unsafe for extra riders. (Check all that apply.) A) tractor, B) all-terrain vehicle, C) pick-up truck cab, D) combine. (B; also A and D if they are not equipped with a manufacturer-installed extra seat.)

\section{Resources}

For more information about these and many other safety topics, contact your county Extension office, or visit the Florida AgSafe Network Web site:

http://www.flagsafe.ufl.edu

"Tractor Fundamentals: Best Practices," North American Guidelines for Children's Agricultural Tasks. For more information, contact the National Children's Center for Rural and Agricultural Health and Safety. Web site: <http://www.nagcat.org>.

"Hand Signals for Agriculture," ASAE Standard S351.

"Operator Controls on Agricultural Equipment," ASAE Standard S335.4.

"Roll-Over Protective Structures (ROPS) for Wheeled Agricultural Tractors," ASAE Standard S383.1.

"Symbols for Operator Controls on Agricultural Equipment," ASAE Standard S304.5.

"Roll-Over Protective Structures (ROPS)," Occupational Safety and Health Administration, OSHA Standard 1928.51

"No Riders" decals may be purchased from the Farm Safety 4 Just Kids organization. Call (515) 758-2827.
The following publications are available at your county Extension office and at the EDIS Web site, $<$ http://edis.ifas.ufl.edu $>$.

(IFAS Publication Numbers are in parentheses after the titles, followed by the Web address to access the publication.)

- Get Started on the Right Foot: Dangers of Bypass Starting (AE299) (On the Web at: http://edis.ifas.ufl.edu/AE173.)

- Filling Gas Cans Safely (AE301) (On the Web at: http://edis.ifas.ufl.edu/AE174.)

- Lighting and Marking Farm Equipment for Road Travel -- Summary of ASAE Standard S279.10 (AE302) (On the Web at: http://edis.ifas.ufl.edu/AE175.)

- Road Safety for Tractors (AE303) (On the Web at: http://edis.ifas.ufl.edu/AE176.)

- Frequently Asked Questions (FAQs) about Rollover Protective Structures (ROPS) (AE304) (On the Web at: http://edis.ifas.ufl.edu/AE177.)

- Avoid The Invisible Hazard: Know About Soil Shear Lines (AE305) (On the Web at: http://edis.ifas.ufl.edu/AE178.)

- Shortcuts are Shortsighted! or Invest Seconds, Save Lives (AE306) (On the Web at: http://edis.ifas.ufl.edu/AE179.)

- Ready or Not? Get Ready with a Tractor Operator Checklist (AE307) (On the Web at: http://edis.ifas.ufl.edu/AE180.)

- Yee-Haa! Formula for a Successful Tractor Rodeo (AE308) (On the Web at: http://edis.ifas.ufl.edu/AE181.)

- Hand-me-down Hazards: Dangers of Used Equipment (AE309) (On the Web at: http://edis.ifas.ufl.edu/AE182.)

- Safety Tips for Tractor Loading and Towing (AE310) (On the Web at: http://edis.ifas.ufl.edu/AE183.) 
- Safer Tractor Operations for Agricultural Employers (Circular 1249) (On the Web at: http://edis.ifas.ufl.edu/AE195.)

- Safer Tractor Operations for Privately Owned and Operated Farms and Ranches (Circular 1250) (On the Web at: http://edis.ifas.ufl.edu/AE196.)

- Safer Tractor Operations for Acreages and Homeowners (Circular 1251) (On the Web at: http://edis.ifas.ufl.edu/AE197.)

- Safer Tractor Operations for Landscape Maintenance and Horticultural Industries (Circular 1252) (On the Web at: http://edis.ifas.ufl.edu/AE198.)

- Safer Tractor Operations for Emergency and Rescue Personnel (Circular 1253) (On the Web at: http://edis.ifas.ufl.edu/AE199.)

- Safer Tractor Operations for Farm Workers and Employees (Circular 1254) (On the Web at: http://edis.ifas.ufl.edu/AE200.)

\section{Appendix 1. Further Comments about the Hazards of Rotating Machine Parts}

In the situation described at the beginning of this publication, a 17-year-old is killed when he becomes entangled in a rotating power take-off (PTO) shaft.

How aware was the young man of the hazard of a rotating PTO shaft? The victim' s knowledge of work-related hazards depended on verbal instruction and observation of the procedures used by the farmer.

The PTO driveline and flywheel shields had been missing during the entire time (six months) the victim had been working on this farm. Considering his age and experience, he may not have been able to recognize that the missing shields created a hazard. Additionally, he had been working alongside an experienced worker, the farmer, while both of them were near the exposed rotating machine parts.

Although the farmer recalled seeing demonstrations where mannequins were entangled and destroyed by unguarded PTO drivelines, he stated he did not realize the seriousness of the entanglement hazard when the tractor engine was operating at idle speed only.

The PTO for the tractor in this incident is rated 540 revolutions per minute (rpm) at 1,900-rpm engine speed. However, even at engine idle speed (about $700 \mathrm{rpm}$ ), the PTO shaft turns at approximately $200 \mathrm{rpm}$ or 3.3 revolutions per second. Even at idle speed an entanglement would occur instantly.

All persons operating or working near PTO-driven machines should recognize the hazard of PTO driveline entanglement and the need for complete driveline shielding systems. Workers should understand that even when the driveline shielding system is complete, safe clearance should be maintained to protect against being caught by undetected sharp edges of damaged shields. Workers should receive training in machine-specific hazard identification for all machines they are exposed to.

From: University of Iowa, Iowa Fatality Assessment and Control Evaluation Program, Case No. 044. 
Table 1. Is a few seconds worth the risk?

\begin{tabular}{||l|l|l||}
\hline \hline $\begin{array}{l}\text { If your risky } \\
\text { shortcut saves: }\end{array}$ & $\begin{array}{l}\text { You save this } \\
\text { much time for } 100 \\
\text { repetitions: }\end{array}$ & $\begin{array}{l}\text { While multiplying } \\
\text { your risk of injury } \\
\text { by 100! }\end{array}$ \\
\hline 3 seconds & 5 minutes & \\
\hline 5 seconds & 10 minutes & \\
\hline 10 seconds & 17 minutes & \\
\hline \hline
\end{tabular}

Table 2. Isn't your safety worth a few extra seconds?

\begin{tabular}{||l|l|l||}
\hline \hline Task & $\begin{array}{l}\text { Time } \\
\text { Invested }\end{array}$ & 100 Repetitions \\
\hline Walking down steps instead of jumping off tractor & 7 seconds & 12 minutes \\
\hline Walking around the PTO instead of stepping over it & 2 seconds & $31 / 3$ minutes \\
\hline $\begin{array}{l}\text { Engaging cylinder locks on combine when working near or } \\
\text { under header }\end{array}$ & 30 seconds & 50 minutes \\
\hline $\begin{array}{l}\text { Getting off mower to pick up something instead of leaning } \\
\text { over to pick it up as you drive by }\end{array}$ & 20 seconds & 33 minutes \\
\hline $\begin{array}{l}\text { Remember: The time you invest in performing a task safely is minimal when you compare it to the } \\
\text { high financial and emotional costs associated with death, injury and permanent disability. }\end{array}$ \\
\hline \hline
\end{tabular}

Table 3. A tractor cannot stop before running over a thrown rider, no matter how slowly it is going.

\begin{tabular}{|c|c|c||}
\hline \hline $\begin{array}{l}\text { Tractor } \\
\text { speed } \\
\text { (miles per } \\
\text { hour) }\end{array}$ & $\begin{array}{l}\text { Stopping } \\
\text { distance } \\
\text { (feet) }\end{array}$ & $\begin{array}{l}\text { How far tractor travels } \\
\text { until the average person } \\
\text { reacts } \\
\text { feet) }\end{array}$ \\
\hline 2 & 6 & 1.5 \\
\hline 5 & 12 & 3.7 \\
\hline 10 & 30 & 7.3 \\
\hline 15 & 44 & 11.0 \\
\hline 20 & 64 & 14.3 \\
\hline
\end{tabular}

Table 4. Size Limits Beyond Which Escort Vehicles Are Required

\begin{tabular}{||l|l|l|l|l|l||}
\hline \hline State & Width & Length & Height & Overhang & Special \\
\hline Alabama & $12 \mathrm{ft}$ & $75 \mathrm{ft}$ & $16 \mathrm{ft}$ & $\begin{array}{l}\text { Rear: } 5 \mathrm{ft} \\
\text { Front: } 10 \mathrm{ft}\end{array}$ & $\begin{array}{l}\text { Blade or bucket extends } \\
\text { beyond the side of the } \\
\text { vehicle }\end{array}$ \\
\hline Florida & $12 \mathrm{ft}$ & $95 \mathrm{ft}$ & $\begin{array}{l}14 \mathrm{ft} 6 \\
\text { in }\end{array}$ & none stated & none stated \\
\hline Mississippi & $12 \mathrm{ft}$ & $99 \mathrm{ft}$ & none & Rear:15 ft & none stated \\
\hline Information obtained from Department of Transportation Permits Division in each of the respective states.
\end{tabular}


Table 5. Tractor Operator Checklist

\begin{tabular}{|c|c|c|c|}
\hline \multicolumn{4}{|c|}{$\begin{array}{l}\text { Tractor Operator Checklist } \\
\text { Directions: This checklist is designed to evaluate a tractor operator's abilities to safely maintain and operate a tractor. } \\
\text { Mark }(x) \text { in the Yes column if the operator can perform the activity, or in the No column if the operator can not perform } \\
\text { the activity. Mark the Not Applicable, NA, column if the activity is not appropriate for this tractor or operation. } \\
\text { Make of Tractor }\end{array}$} \\
\hline Activity or Condition & Yes & No & NA \\
\hline \multicolumn{4}{|l|}{ Personal Safety Precaution } \\
\hline \multicolumn{4}{|c|}{ Only operate the tractor if you are physically and mentally alert. } \\
\hline \multicolumn{4}{|l|}{ Wear close-fitting clothes and proper shoes. } \\
\hline \multicolumn{4}{|c|}{$\begin{array}{l}\text { Eat and drink in moderation, and do not operate the tractor if you have been drinking } \\
\text { alcohol or taking drugs or medication. }\end{array}$} \\
\hline \multicolumn{4}{|l|}{ Use basic hand signals. } \\
\hline \multicolumn{4}{|c|}{ Preparing the Tractor and Equipment for Safer Operation } \\
\hline \multicolumn{4}{|l|}{ Don't operate the tractor in closed buildings. } \\
\hline \multicolumn{4}{|c|}{ Check the location and condition of the fire extinguisher. } \\
\hline \multicolumn{4}{|l|}{ Check the location and condition of the first aid kit. } \\
\hline \multicolumn{4}{|l|}{ Read and understand decals on the tractor. } \\
\hline \multicolumn{4}{|c|}{ Make sure that the shield for the PTO and other parts are in place. } \\
\hline \multicolumn{4}{|c|}{ Keep steps and platform free of dirt, grease, and debris. } \\
\hline \multicolumn{4}{|c|}{ Check if the slow-moving vehicle emblem is in place, clean, and not faded. } \\
\hline \multicolumn{4}{|l|}{ Test lights to be sure they're working. } \\
\hline \multicolumn{4}{|l|}{ Check for loose tools and parts. } \\
\hline \multicolumn{4}{|l|}{ Clean the windows. } \\
\hline \multicolumn{4}{|l|}{ Read and understand all controls. } \\
\hline \multicolumn{4}{|l|}{ Check the condition and pressure of all tires. } \\
\hline \multicolumn{4}{|l|}{ Check oil level; add oil as needed. } \\
\hline \multicolumn{4}{|c|}{ Check coolant level; add coolant as needed. Do not remove radiator cap when hot. } \\
\hline \multicolumn{4}{|c|}{$\begin{array}{l}\text { Check the battery's electrolyte level and add battery water as needed. Don't use } \\
\text { matches around the battery and don't smoke. }\end{array}$} \\
\hline \multicolumn{4}{|l|}{ Check, clean, coat and tighten battery connections. } \\
\hline \multicolumn{4}{|c|}{ Locate all grease fittings and clean and lubricate them. } \\
\hline \multicolumn{4}{|c|}{ Refuel the tractor, making sure that the engine is cool and refrain from smoking. } \\
\hline \multicolumn{4}{|l|}{ Adjust wheel width. } \\
\hline Add or remove weights. & & & \\
\hline Check if equipment has been properly serviced & & & \\
\hline Starting, Operating, Stopping Tractor and Equipm & & & \\
\hline Make sure that the area is clear of people, pets & & & \\
\hline Adjust seat for comfort. & & & \\
\hline Start the tractor. & & & \\
\hline Check gauges for proper readings. & & & \\
\hline Listen for unusual sounds and shut off the engir & & & \\
\hline Check brakes. & & & \\
\hline Warm engine before applying a heavy load. & & & \\
\hline Never operate the tractor from the ground. & & & \\
\hline Raise, lower and extend the drawbar. & & & \\
\hline Clean and oil PTO shaft and splines. & & & \\
\hline Clean, connect and disconnect hydraulic lines. & & & \\
\hline Connect and disconnect electrical connections. & & & \\
\hline
\end{tabular}


Table 5. Tractor Operator Checklist

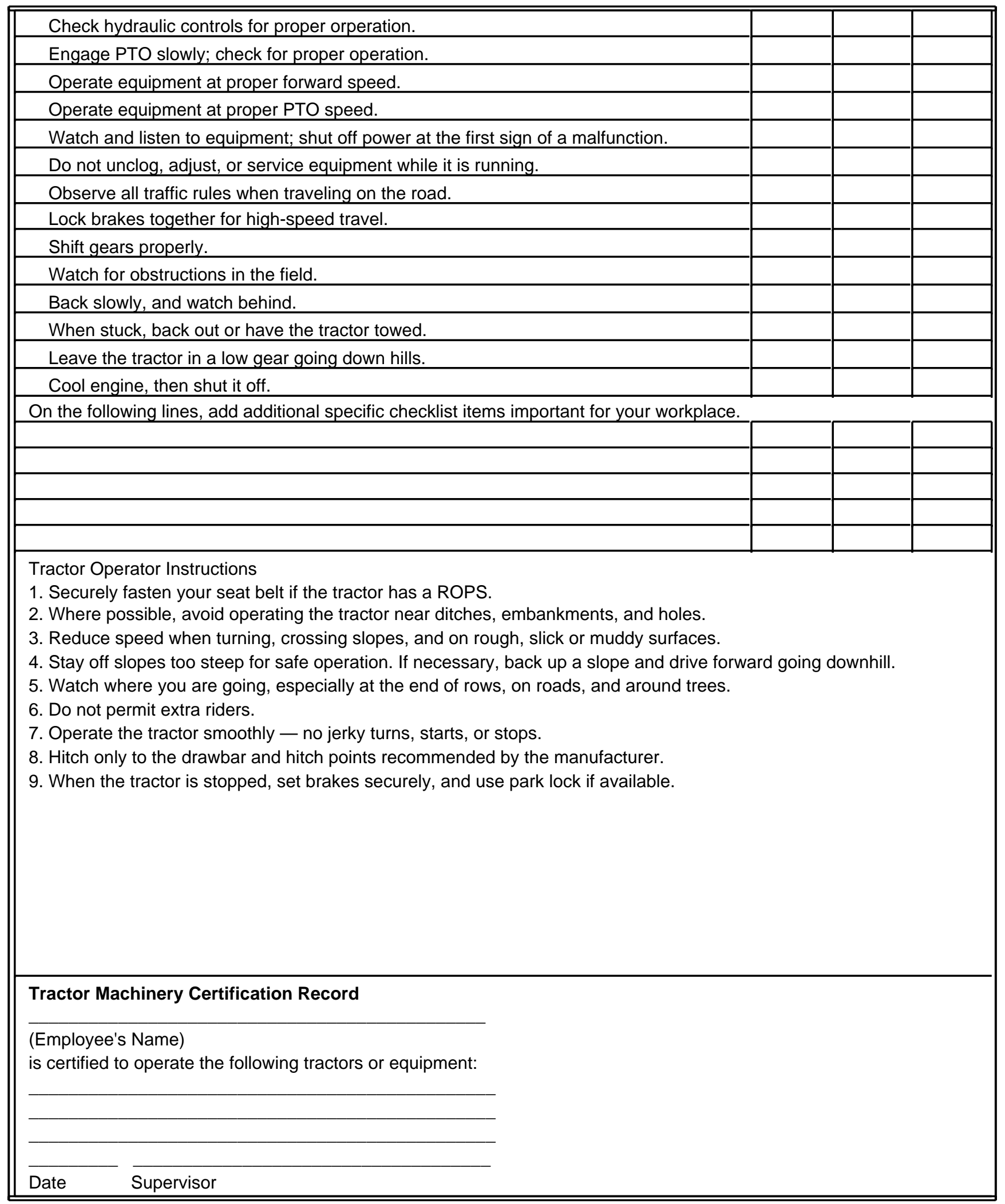


Table 6.

\begin{tabular}{|c|c|c|}
\hline & $\begin{array}{l}\text { Tractor Safety Pre-Post Test } \\
\text { Circle the correct answer or write it in the space provided. }\end{array}$ & \\
\hline 1. & Most injuries to tractor operators are preventable. & True or False. \\
\hline 2. & $\begin{array}{l}\text { The safety features on modern tractors can protect the } \\
\text { operator from anything. }\end{array}$ & True of False. \\
\hline 3. & $\begin{array}{l}\text { Shortcuts usually save very little time while increasing } \\
\text { danger to the operator. }\end{array}$ & True or False. \\
\hline 4. & A ROPS will prevent a tractor overturn. & True or False. \\
\hline 5. & $\begin{array}{l}\text { How often should oil, fuel, and other fluid levels be } \\
\text { checked? }\end{array}$ & \\
\hline 6. & $\begin{array}{l}\text { Discomfort is: } \\
\text { A) A normal part of work which keeps the operator alert } \\
\text { and makes him work harder, or } \\
\text { B) Something that tires and distracts the operator and can } \\
\text { make work less safe. }\end{array}$ & A $B$ \\
\hline 7. & Extra riders on tractors are often injured in what way? & \\
\hline 8. & $\begin{array}{l}\text { At what level should warning lights be placed on tractors } \\
\text { and other equipment for operation on public roads? } \\
\text { A) As low as possible, } \\
\text { B) Motorist's eye level, or } \\
\text { C) as high as possible. }\end{array}$ & A $B \quad$ C \\
\hline 9. & $\begin{array}{l}\text { The majority of tractor-automobile collisions occur: } \\
\text { A) during wet weather, } \\
\text { B) at night, or } \\
\text { C) on dry days in broad daylight. }\end{array}$ & A $B \quad C$ \\
\hline 10. & $\begin{array}{l}\text { The faster you are driving the less likely you are to } \\
\text { jackknife. }\end{array}$ & Ture or False. \\
\hline
\end{tabular}

